\title{
Do quarto de empregada à varanda gourmet: plantas de apartamento em Florianópolis (1954- 2008)
}

\author{
From maids' rooms to gourmet balconies: apartment \\ layouts in Florianópolis (1954-2008)
}

\section{Gabriel Vespucci \\ Renato Saboya}

\section{Resumo}

$\mathbf{E}$

ste estudo tem como base amostra de 55 plantas de apartamentos dos arquivos da Prefeitura de Florianópolis (SC). Foram analisados apartamentos com dois ou três dormitórios em edifícios multifamiliares de quatro ou mais pavimentos, construídos na área central insular em Florianópolis e aprovados no período entre 1954 e 2008 . O objetivo foi identificar as alterações morfológicas, ao longo das décadas, e dos padrões de organização das plantas segundo sua setorização e hierarquização dos ambientes. Os resultados mostraram variações e tendências ao longo das décadas analisadas, tais como grande variação dos percentuais das áreas dos setores (social, íntimo e serviços), principalmente a partir do início da década de 2000. Os cálculos mostraram também que medidas de integração $(\mathrm{HH})$ das unidades mantiveram-se estáveis até o início da década de 2000, quando aumentam expressivamente, muito provavelmente pela maior presença de apartamentos com sala aberta para cozinha, que cresce em importância e centralidade. As medidas de isovista média e de isovista da porta de entrada indicaram tendências semelhantes. Essas alterações demonstraram aderência entre a estrutura espacial desse tipo de unidade habitacional e as alterações do perfil socioeconômico dos diferentes extratos da população ao longo das décadas, bem como mudanças em aspectos culturais como relações de sociabilidade, hábitos e disposições.

Palavras-chave: Plantas de apartamentos. Unidade habitacional. Visibilidade. Sintaxe espacial.

\begin{abstract}
This study is based on a sample of 55 apartment plans from the archives of the Municipality of Florianópolis (SC). Two-and three-bedroom apartments in buildings with four or more stories built in the central area of Florianópolis, and approved in the period between 1954 and 2008, were analysed. The goal was to identify the morphological changes that occurred over those four decades, and the changes in the spatial patterns of plans, considering their sectors (social, intimate and services) and hierarchies. The results showed certain variations and trends over the decades, such as a wide variation in the sectors' areas percentages, mainly from the early 2000s. The calculations also showed that integration measures $(\mathrm{HH})$ were relatively stable until the early 2000s, when they increased significantly, most probably due to a greater presence of open-plan kitchens, which grew in importance and centrality. The average Isovist size and Isovist size from the main entrance door showed similar trends. These changes have shown an adherence between the spatial structure of these types of residential units and socioeconomic changes in different social groups over the decades, as well as cultural aspects such as sociability relations, habits and dispositions.
\end{abstract}

Recebido em 23/03/19 Aceito em 23/06/19

Keywords: Apartment plans. Housing unit. Visibility. Space syntax.

VESPUCCI, G.; SABOYA, R.Do quarto de empregada à varanda gourmet: plantas de apartamento em Florianópolis (1954-305 2008). Ambiente Construído, Porto Alegre, v. 20, n. 2, p. 305-322, abr./jun. 2020.

ISSN 1678-8621 Associação Nacional de Tecnologia do Ambiente Construído.

http://dx.doi.org/10.1590/s1678-86212020000200401 


\section{Introdução}

Cerca de quarenta anos separam os dez andares do primeiro arranha-céu em Chicago das primeiras torres no Rio de Janeiro e em São Paulo (SEGAWA, 2002). O advento do elevador de segurança, o uso do concreto armado e o aumento no valor da terra nas áreas centrais são alguns dos principais impulsionadores da habitação multifamiliar verticalizada no Brasil (REIS FILHO, 1983; TRAMONTANO, 1993).

O uso residencial nas torres mira primeiramente a classe média e logo alcança as classes mais abastadas (LEMOS, 1996), após a superação de uma resistência inicial de uma sociedade pouco afeita àquilo que Segawa (2002) denomina "promiscuidade" ou "coletivismo" da moradia em prédios de apartamento em altura. Essa mesma moradia se consolida ao favorecer a amplidão, o conforto e a rígida separação entre zonas de serviço e sociais da casa unifamiliar (BRUAND, 2002). Melhor dizendo, representa uma tentativa, bem-sucedida financeiramente, sabe-se hoje, de reproduzir e simplificar o casarão eclético, cujas características são herdadas dos esquemas da casa burguesa da Belle-Époque parisiense do século XIX: "Os primeiros edifícios de apartamentos tiveram suas plantas norteadas pela ideia de empilhar, em um mesmo terreno, várias casas, todas iguais entre si [...]" (LEMOS, 1996, p. 79).

Afirmando que determinadas particularidades do comportamento e do modo de vida são resistentes a mudanças, Rapoport (1969) indica que o valor de prestígio de uma forma pode decretar o abandono da antiga, mesmo tendo utilidade real. Inversamente, o mesmo prestígio, mas agora característico de coisas antigas, pode impedir que a forma, mesmo sem validade objetiva, obsoleta, seja substituída por uma nova. Essas atitudes são direcionadas culturalmente, mas, para o autor, possuem um elemento aparente de perenidade pouco estudado.

Quando esteve a trabalho no Brasil, entre 1840 e 1846, o jovem engenheiro francês Louis-Léger Vauthier, em carta ao arquiteto e editor Cesar Daly, decretou: "Assim, quem viu uma casa brasileira, viu quase todas!" (VAUTHIER, 1981, p. 37). A despeito do alcance possivelmente limitado de sua percepção — ignorando sobrados de outras regiões do território brasileiro e também a tipologia rural —, a frase de Vauthier, relacionada à forma rígida, ao conforto ambiental e às disposições internas da moradia, encontra respaldo em outros contextos e autores. Lewcock (1986) percebe que quando a forma de torre se torna o padrão estabelecido para a moradia, dentro de um contexto social conservador, caso de Shibam, no Iêmen, ela tende a permanecer por longo tempo, mesmo quando perdem relevância as causas que a originaram. Na mesma linha, Braudel (1995, p. 238) afirma: "Em suma, uma 'casa', seja ela qual for, dura e não para de testemunhar a lentidão de civilizações, de culturas obstinadas em conservar, em manter, em repetir.". Não seria diferente para o caso deste trabalho. Sobre a residência burguesa francesa que inspira o apartamento brasileiro, Perrot (1992, p. 310) diz que "O interior de cada apartamento oferece uma racionalidade que por muito tempo não será igualada. Compreende obrigatoriamente um espaço público de representação, um espaço privado para a intimidade familiar e espaços de rejeição [...]".

Segundo Queiroz e Tramontano (2009), há uma indiscutível semelhança relativa à separação e disposição dos cômodos entre o apartamento contemporâneo brasileiro e a habitação burguesa parisiense do século XIX. A divisão física da casa em três zonas (conforme a Figura 1) é, possivelmente, o mais visível aspecto de uma padronização do modo de produzir e viver em habitações. Independentemente da localização do imóvel, da renda de seus moradores e da área construída, o chamado modelo tripartido, constituído de zona social, íntima e de serviços, atinge a quase totalidade dos imóveis residenciais em altura produzidos nas últimas décadas no Brasil (VILLA, 2004).

Há cem anos são produzidos apartamentos seguindo esse modelo, fortalecido com a facilitação a o financiamento estatal e profissionalização da construção civil, e isso se intensifica a partir de 1964, com a criação do Banco Nacional da Habitação (BNH). A tripartição da habitação é acompanhada de mais cinco pontos recorrentes nos apartamentos residenciais: divisão da planta em cômodos, vinculação de atividades a cômodos específicos, hierarquia entre espaços, articulação por meio de corredores e dispositivos de circulação e hierarquização dessas circulações, separando moradores e empregados (TRAMONTANO, $1998^{1}$ apud QUEIROZ, 2008).

${ }^{1}$ TRAMONTANO, M. C. Novos modos de vida, novos espaços de morar, Paris, São Paulo, Tokyo: uma reflexão sobre a habitação contemporânea.São Paulo, 1998. Tese (Doutorado em Arquitetura e Urbanismo) - Faculdade de Arquitetura e Urbanismo, Universidade de São Paulo, São Paulo, 1998.

306 Vespucci, G.; Saboya, R. 
Figura 1 - As três zonas da habitação*

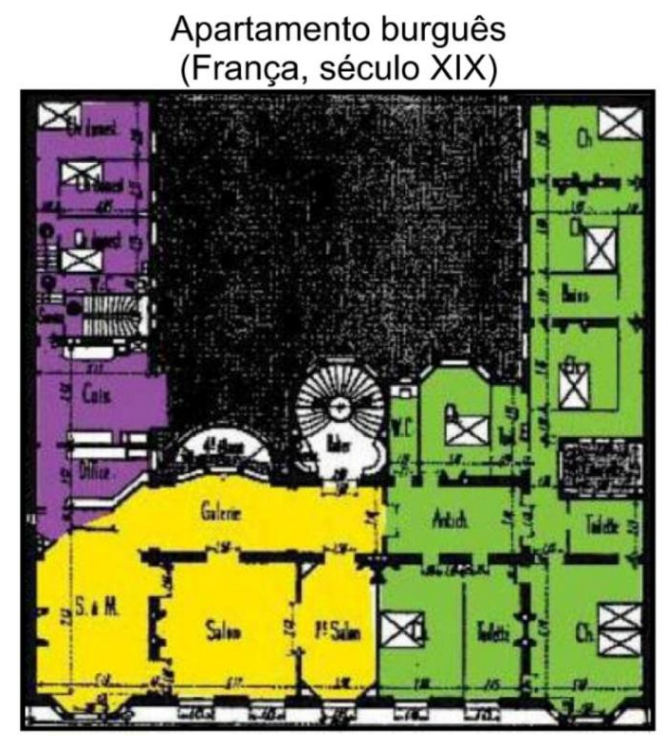

Fonte: elaboração própria a partir de Eleb (2002) e Requena (2007).

Nota: *as cores utilizadas diferem do padrão usado no restante do artigo para denotar os setores em consonância à figura original (à esquerda).
Apartamento atual (Brasil, século XXI)

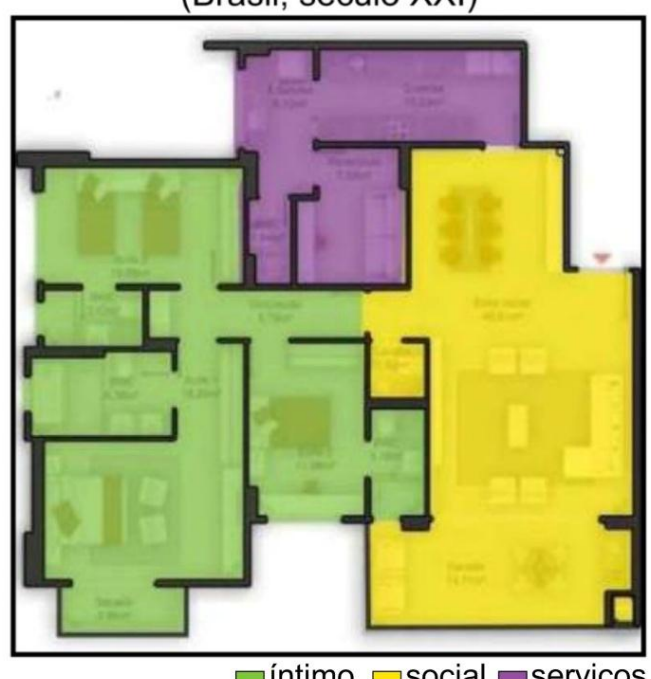

øíntimo $\square$ social $\square$ serviços

O apartamento é a modalidade domiciliar que mais cresce no país. Enquanto a população brasileira cresceu perto de $72 \%$ de 1980 a 2018, o número de apartamentos em edifícios residenciais passou de 1,8 milhão a 9,8 milhões de unidades, um incremento de $444 \%$, ao passo que o número de casas cresceu $161 \%$ do total no mesmo período. Em 2018, aproximadamente 13,8\% das moradias brasileiras eram apartamentos. Entre 1970 e 2018, o número de pessoas por domicílio caiu 44,5\%, de 5,28 para aproximadamente 2,93. Cada vez menos representativa é a tradicional família nuclear, composta de mãe, pai e filhos. Novos arranjos familiares foram forjados: casais sem filhos, solteiros, coabitantes sem laços parentais, etc. $\mathrm{O}$ arranjo doméstico chamado de unipessoal, que representa a pessoa morando sozinha, saltou de 5,8\% para $15,5 \%$ entre 1970 e 2018 (BERQUÓ, 1998; ALVES, 2004; INSTITUTO..., 2019).

A moradia em altura e a verticalização, além de representarem uma nova forma de morar, acabaram por revolucionar, conforme aponta Ramires (2011), a fisionomia das cidades e, mesmo objeto de polêmicas sobre seus aspectos positivos e negativos, são típicas da modernidade.

No fim dos anos de 1950 surgem os primeiros "arranha-céus" residenciais de Florianópolis. Edifícios de 4 até 12 pavimentos começam a despontar na paisagem da porção central insular da cidade. Durante essa década a população do município tem grande incremento, saltando de 51.317, em 1950, para 98.520 habitantes, dez anos depois.

Se Florianópolis teve uma verticalização habitacional relativamente tardia se comparada a outras cidades de porte médio e grande do sul-sudeste brasileiro, ela foi intensa, a exemplo de outras cidades litorâneas catarinenses. Segundo dados do IBGE (INSTITUTO..., 2010), Balneário Camboriú $\left(2^{\circ}\right)$, Florianópolis $\left(6^{\circ}\right)$, São José $\left(10^{\circ}\right)$ e Itapema $\left(12^{\circ}\right)$ estão entre os 15 municípios brasileiros com maior percentual de apartamentos dentre os domicílios.

Mesmo com essa característica verticalizada das cidades costeiras catarinenses, são raras as pesquisas que tratam do interior da moradia em prédios, do apartamento enquanto objeto de estudo, ao contrário de grandes centros como São Paulo e Rio de Janeiro, pioneiros na habitação em altura, e de cidades grandes e médias, como Brasília, Belo Horizonte, Porto Alegre, Recife, Goiânia, Ribeirão Preto (SP), Vitória (ES) e Viçosa (MG), que contam com estudos da mesma natureza (ver, por exemplo, Pinho (2005), Villa (2008) e Griz (2012)).

Assim, realizou-se pesquisa de caráter exploratório buscando padrões, ideias ou hipóteses explicativas de como a espacialidade do apartamento florianopolitano se mantém ou se altera ao longo das décadas. Para isso, foram utilizadas categorias de interesse, divididas em dimensões morfológicas e sintático-espaciais. A existência ou não de determinados cômodos, bem como alterações em seu tamanho, permitem verificar o 
valor que é dado às atividades que nele se desenvolvem, ou mesmo se tais atividades ainda fazem parte do cotidiano dos moradores. A permeabilidade física e a visibilidade, por sua vez, afetam diretamente a forma como as residências são experimentadas por seus usuários: moradores e visitantes. As informações visuais fornecidas para o observador estão relacionadas ao controle de permeabilidade e visibilidade do espaço físico da residência e, consequentemente, com as necessidades de privacidade (GÜNEY, 2007). Além de mais silenciosos e vazios, os espaços domésticos mais segregados correspondem, em geral, aos lugares em que se quer manter maior nível de privacidade ou de isolamento, caso dos quartos de empregada e banheiros das suítes, por exemplo; no caso da família tradicional, o quarto dos pais também costuma ter essa característica, traduzindo uma simbologia de poder e refletindo uma estrutura social hierarquizada e rígida (HANSON, 1998). O número de anéis — possibilidade de circuitos completos, internos à habitação — e a quantidade de espaços de uso comum, ao contrário, favorecem a integração dos espaços, criando oportunidade de encontros sociais e familiares (DAWSON, 2002). Assim, mudanças no nível de visibilidade e acessibilidade dos espaços também podem ser reveladoras de mudanças na sua apropriação e em sua importância relativa ao longo do tempo, mesmo que suas áreas não tenham se modificado.

Dessa forma, o objetivo geral foi investigar as transformações e permanências das plantas de apartamentos residenciais em Florianópolis, desde a década de 1950 até os anos de 2000, por meio de:

(a) identificação de padrões recorrentes de organização das plantas segundo sua setorização e hierarquização dos ambientes;

(b) identificação da presença ou não dos diferentes cômodos, bem como a quantificação de sua área e proporção na amostra; e

(c) investigação de como esses parâmetros se modificaram ao longo do tempo, buscando determinar se há períodos claros de transição.

\section{Método}

Em linhas gerais, o estudo obedeceu aos passos e ao método descritos a seguir:

(a) definição da amostra a ser estudada: apartamentos de 2 e 3 quartos em Florianópolis, localizados na área central insular, construídos entre 1954 e 2008;

(b) coleta de dados, redesenho e análise das peças gráficas;

(c) definição das dimensões de análise: morfológica e sintático-espacial;

(d) análise e comparação dos dados; e

(e) resultados e conclusões.

\section{Universo estudado}

Por ter Florianópolis uma ocupação bastante heterogênea, ser pouco densa e de urbanização muito dispersa (MANCINI, 2008), incluindo ilha e continente, optou-se pelo recorte geográfico na área central insular, delimitando como objeto de estudo os bairros adjacentes ao Morro da Cruz. Entendeu-se também que outras partes do município, mesmo possuindo prédios de apartamentos, como os balneários do norte e do sul, deveriam ser excluídos da presente análise. Esses locais, mesmo com crescente número de moradores fixos, são voltados a uma ocupação de veraneio, o que poderia introduzir variação excessiva nos resultados da pesquisa, quando comparados a prédios nas áreas centrais. Lagoa da Conceição, João Paulo e Saco Grande, mais próximos e com utilização aparentemente compatível com o centro da cidade, possuem ocupação recente de prédios residenciais, tendo menos a contribuir em termos de passagem no tempo. Mais recente ainda é a ocupação do Rio Tavares no que diz respeito aos edifícios multifamiliares. Assim, conforme se vê na Figura 2, a abrangência da pesquisa ficou limitada à circunscrição dos seguintes bairros: Centro, Agronômica, Trindade, Itacorubi, Córrego Grande, Pantanal, Carvoeira e Saco dos Limões. Os bairros Santa Mônica e José Mendes fazem parte da área delimitada, mas não possuem edifícios da natureza estudada, tendo sido, dessa forma, desconsiderados.

Quanto ao recorte temporal, os primeiros prédios altos residenciais de Florianópolis começaram a ser construídos na década de 1950. A data de 1954 marca a aprovação do primeiro projeto desse tipo na prefeitura: o Edifício Meridional, localizado na esquina da Rua João Pinto com a Praça XV de Novembro. Há um número considerável de edifícios residenciais baixos de 3 e 4 pavimentos anteriores a 1954, porém seus projetos não foram encontrados na Prefeitura. Para que todos os edifícios estudados tivessem seus

308 Vespucci, G.; Saboya, R. 
projetos executados até a conclusão deste estudo, arbitrou-se o ano 2008 como limite recente do recorte temporal. Assim, durante a seleção da amostra, o recorte temporal acabou sendo estabelecido como o intervalo entre 1954 e 2008.

Definidas as abrangências geográfica e temporal, restou delimitar o tipo ou os tipos de unidade habitacional a serem estudados.

Para pesquisa de tipificação a respeito do produto imobiliário ofertado no Brasil, Brandão (2003) construiu uma base de dados com mais de 3 mil plantas de apartamentos, sendo 571 somente na cidade de Florianópolis. Dessas, 77\% são de 2 ou 3 dormitórios, fato que direcionou o recorte de exemplares na pesquisa. Ao mesmo tempo, em pesquisa realizada nos arquivos da Secretaria Municipal de Meio Ambiente e Desenvolvimento Urbano da Prefeitura de Florianópolis (SMDU/PMF), foram encontrados projetos de apenas 5 edificações multifamiliares com três ou mais pavimentos aprovados na década de 1950 .

Como há grande heterogeneidade nos edifícios de apartamentos nas décadas seguintes, principalmente no tocante a padrão social e área, corria-se o risco de gerar comparações descabidas entre, por exemplo, um apartamento de um dormitório em um conjunto habitacional e um apartamento de quatro suítes em prédio de um apartamento por andar.

Os critérios para "[...] permitir comparação e certo grau de generalização [...]" (MILES; HUBERMAN, 1994, p.34, tradução nossa) foram: possuir dois ou mais apartamentos por andar, três ou mais andares de apartamentos, dois ou três dormitórios íntimos, um ou dois banheiros íntimos e não ter sido realizado por companhia estatal de habitação. Todas essas características, inclusive, já se fizeram presentes nos cinco prédios de apartamentos que forneceram 7 plantas de apartamentos aprovadas ainda nos anos de 1950, e foram pensadas para abranger aqueles apartamentos mais recorrentes no recorte temporal, de forma a representar aproximadamente aqueles mais explorados pelo mercado.

\section{Seleção da amostra}

O processo de seleção da amostra confronta dados da Prefeitura relativos à concessão da certidão de ocupação, também conhecida por "Habite-se", ao longo do tempo e por bairros com a distribuição geográfica dos prédios que atendem aos critérios preestabelecidos.

A confrontação das informações de localização x tempo e localização x requisitos amostrais conduziu a seleção da amostra, dentro de um banco de 78 edifícios e 144 plantas. O número total, 55 unidades, coincide com aproximadamente uma unidade por ano do recorte temporal (1954 a 2008), em média. A Figura 3 ilustra a distribuição espacial dos dados da Tabela 1.

\section{Figura 2 - Localização do recorte geográfico}

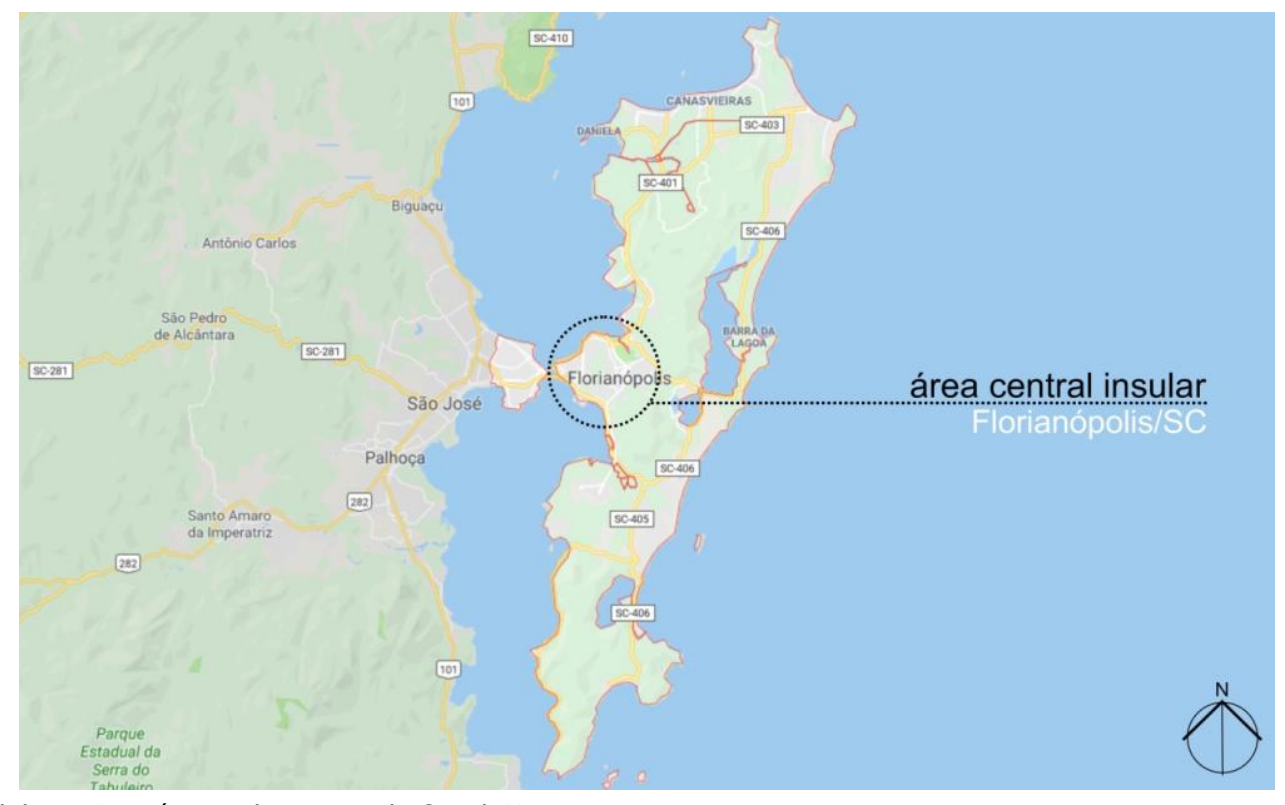

Fonte: elaboração própria sobre mapa do GoogleMaps. 
Figura 3 - Localização das unidades - período 1954-2008

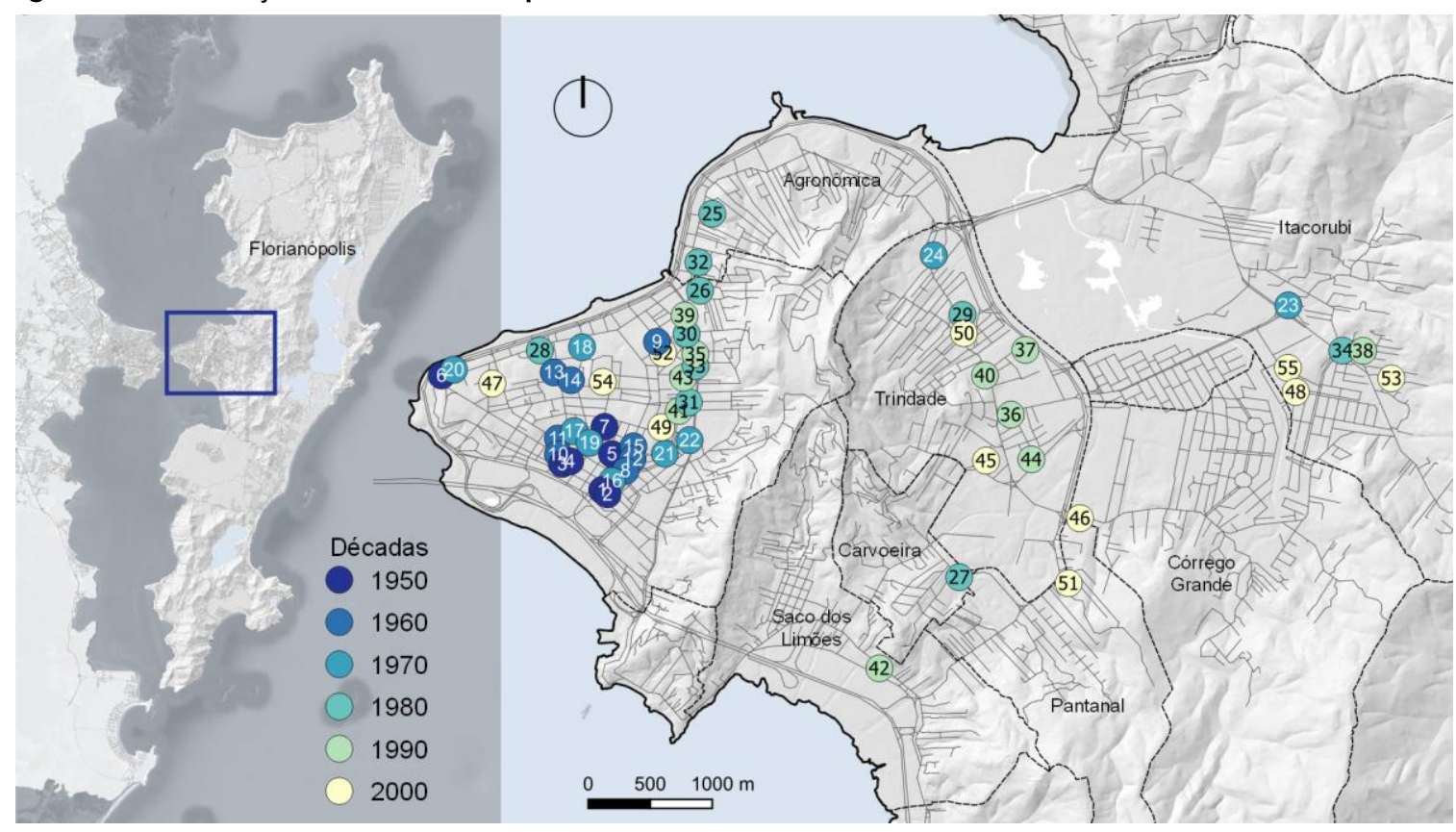

Fonte: elaboração própria sobre dados da Prefeitura Municipal de Florianópolis e Google Earth.

Tabela 1 - Distribuição da amostra selecionada

\begin{tabular}{c|c|c|c|c|c|c}
\hline Bairro / Década & $\mathbf{1 9 5 0}$ - 59 & $\mathbf{1 9 6 0}$ - 69 & $\mathbf{1 9 7 0}$ - 79 & $\mathbf{1 9 8 0}$ - 89 & $\mathbf{1 9 9 0}$ - 99 & $\mathbf{2 0 0 0}$ - 09 \\
\hline Centro & 7 & 8 & 7 & 6 & 4 & 4 \\
Agronômica & - & - & - & 1 & - & - \\
Trindade & - & - & 1 & 1 & 4 & 2 \\
Itacorubi & - & - & 1 & 1 & 1 & 3 \\
Córrego Grande & - & - & - & - & - & 1 \\
Pantanal & - & - & - & - & - & 1 \\
Carvoeira & - & - & - & 1 & - & - \\
Saco dos Limões & - & - & - & - & 1 & - \\
\hline TOTAL & 7 & 8 & 9 & 10 & 10 & 11 \\
\hline
\end{tabular}

\section{Coleta de dados, digitalização e redesenho}

Após a definição da amostra, foram coletados os dados nos arquivos da Prefeitura e as plantas foram redesenhadas em formato dwg para análise morfológica por meio de medições quantitativas e para preparação dos arquivos para o software DepthMap, para uso de técnicas analíticas da Sintaxe Espacial.

\section{Dimensões de análise}

As dimensões de análise tratam de aspectos morfológicos (de recorrência ou de distinção) na análise de peças gráficas (SCHNEIDER, 1998; BRANDÃO; HEINECK, 2004; PEDRO, 1999; VAN HOOGDALEM et al., 1985) e sintático-espaciais (HILLIER; HANSON, 1984; HANSON, 1998; DAWSON, 2002; CUNHA, 2012). São elas:

(a) dimensões morfológicas: área média útil das unidades; percentual dos setores internos (social, íntimo e de serviços); e existência, quantificação, percentual e frequência dos cômodos das unidades; e

(b) dimensões sintático-espaciais: integração $(\mathrm{HH})$ média; percentual da área das isovistas; isovista desde a porta de entrada das unidades; e forma dos grafos justificados simplificados (que expressa o padrão de relações entre setores da unidade por meio gráfico).

Complementarmente aos aspectos morfológicos mais tradicionais, foram utilizados conceitos configuracionais da sintaxe espacial (HILLIER; HANSON, 1984; HANSON, 1998), que trata não da forma 
enquanto geometria, mas das relações entre os diferentes pontos dessa forma (SPERLING, 2008). Análises baseadas nessa ótica têm se mostrado capazes de compreender como o espaço arquitetônico influencia alguns aspectos do comportamento. A Teoria da Sintaxe Espacial traz a integração como seu mais relevante conceito e medida espacial. Para entendê-la, entretanto, é útil examinar antes o conceito de distância topológica, que é aquela determinada pelo número de mudanças necessárias de ambientes para ir de um espaço a outro (EVANS; LEPORE; SCHROEDER, 1996). Assim, a profundidade média de um espaço é medida pela quantidade total de passos topológicos necessários para alcançar todos os outros espaços do sistema, dividida pelo número de espaços menos um. A integração representa a propriedade de um espaço de estar, em média, menos distante topologicamente de todos os demais e, no caso do espaço interno da arquitetura, é uma boa aproximação do seu grau de acessibilidade, ou seja, revela uma relação hierárquica daquele ponto ou cômodo em relação aos outros. Por isso, permite examinar a influência da disposição espacial sobre o movimento e a interação social (DAWSON, 2002), uma vez que esses fenômenos são intimamente relacionados à facilidade de acesso a um espaço com poucas mudanças de direção. Nos espaços mais integrados, ditos também mais rasos, o acesso tende a ser mais fácil e direto relativamente aos outros do mesmo sistema e, por isso, costumam ser os locais de maior movimentação e encontro entre os usuários, sejam os moradores e visitantes de um apartamento, sejam os pedestres em uma área urbana. Um espaço mais segregado ou com maior profundidade, por outro lado, é aquele menos central, que impõe maior distância, não métrica, mas topológica, para acessá-lo.

Outro conceito importante para este estudo é o de isovistas, que são polígonos que representam toda a área visível a partir de um ponto do espaço (Figura 4). A área das isovistas investiga o grau de interferência ou não das barreiras visuais presentes nos espaços, bem como a sensação do quanto um espaço é percebido como espaçoso ou apertado (WIENER; FRANZ, 2005). Neste estudo, elas foram aplicadas de duas maneiras: a relação entre a área média da isovista e a área do apartamento (Iso/A) mostra o quanto a planta prioriza visuais amplos ou restritos, proporcionalmente ao tamanho total da unidade. A isovista da porta de entrada (IsoPE) mostra o quanto é revelado para um visitante assim que este chega ao apartamento (mesmo que não o adentre) e, assim, dá indícios das relações de intimidade e exposição estabelecidas pela planta.

Por fim, os grafos justificados simplificados (Figura 5) foram adotados para analisar a configuração interna geral das unidades. Neles, elege-se um espaço a partir do qual o grafo será estruturado (nesse caso, a entrada principal do apartamento) e, a partir dele, cada ambiente é representado por um nó, e cada conexão direta entre eles por um vértice. Todos os ambientes diretamente ligados ao espaço "raiz" estão a um passo topológico dele e, por isso, são alinhados ao nível 1 do grafo. Todos os espaços conectados aos espaços do nível 1, mas não ao espaço "raiz", estão a 2 passos topológicos deste último e, portanto, são alinhados ao nível 2 do grafo, e assim por diante. Dessa forma, o grafo justificado mostra visualmente o quão profundo ou raso cada ambiente está do espaço raiz, e também permite uma leitura mais global da distribuição dos espaços em termos de profundidade em relação à entrada principal.

Figura 4 - Exemplo de duas isovistas a partir de dois pontos distintos em um mesmo espaço
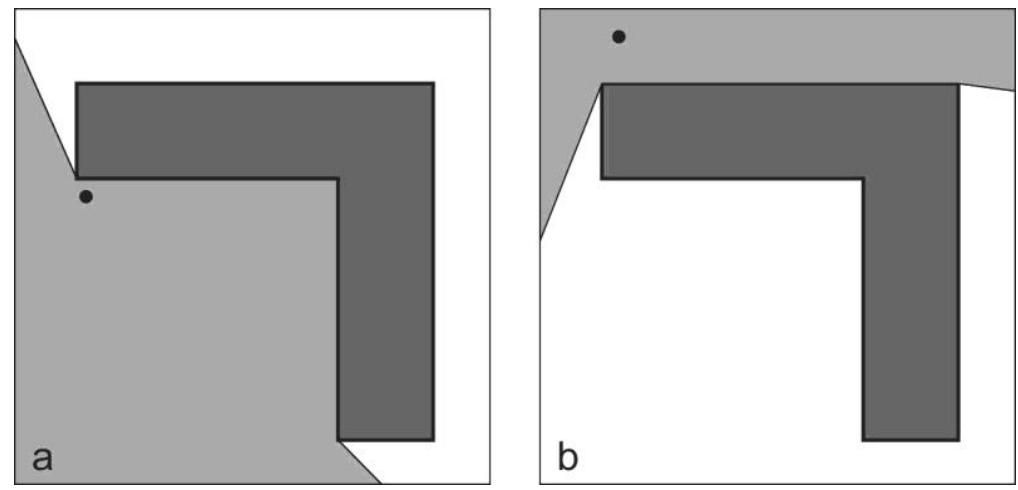

Fonte: Saboya et al. (2014). 
Figura 5 - Exemplos de grafos justificados

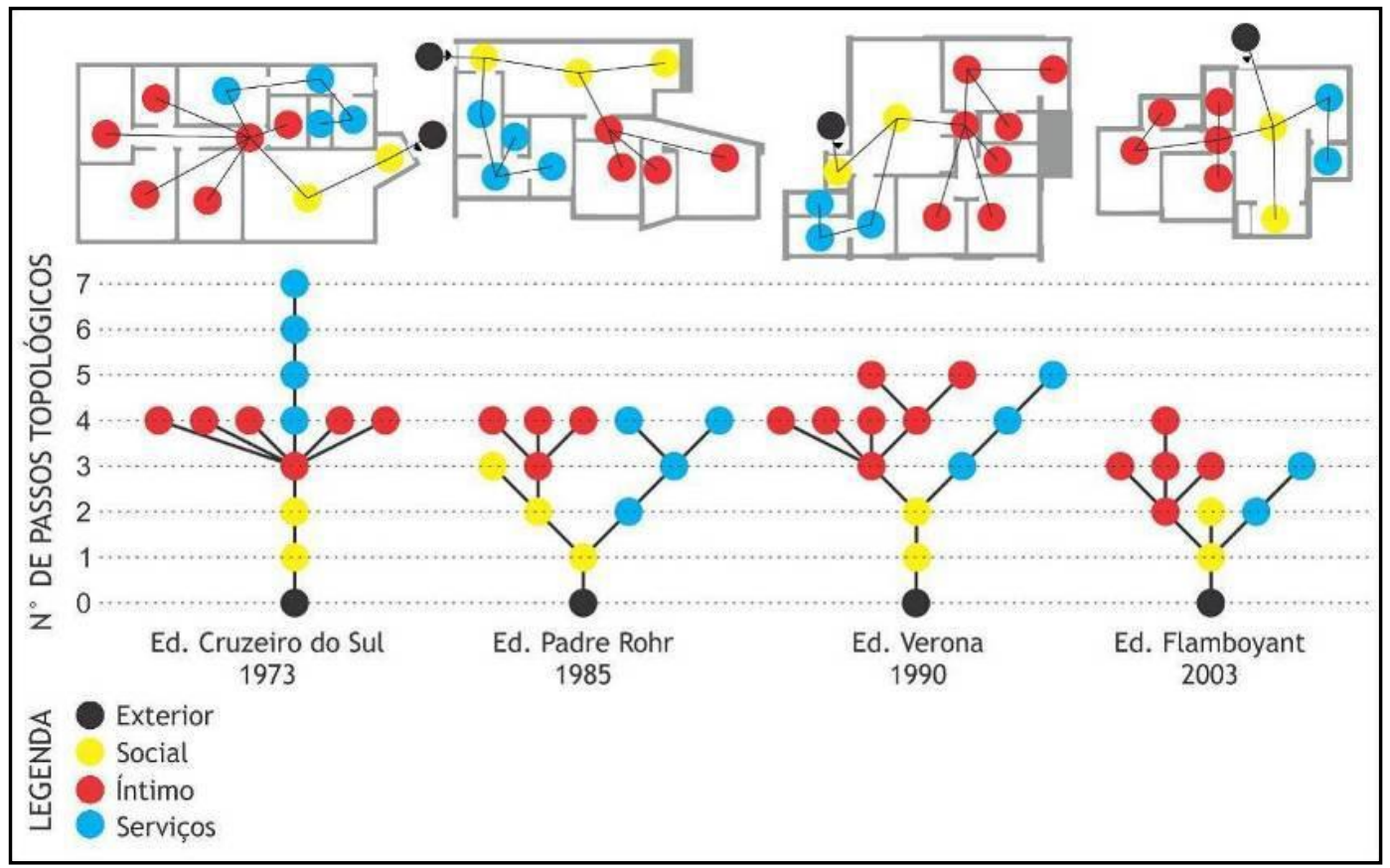

\section{Análises}

Os resultados foram analisados e apresentados em forma de gráficos de barras com as unidades em sequência cronológica (quando é cabido), texto analítico, tabela com resumo ou médias por década das informações extraídas do gráfico e da ilustração de casos mais representativos ou de destaque de cada dimensão de análise. Também foram cruzados resultados de diferentes dimensões para a melhor compreensão de fenômenos funcionando em conjunto.

\section{Resultados e discussões}

\section{Área das unidades e percentual dos setores}

A área dos apartamentos não foi levada em consideração para a composição da amostra. Não chega a surpreender, uma vez que as tipologias da amostra são justamente as mais comuns ( 2 e 3 dormitórios), o fato de que o menor e o maior apartamento estão dentro do intervalo mais comum de áreas da base de dados de Brandão (2003): 70\% dos apartamentos, considerando diversas capitais, têm área entre $40 \mathrm{~m}^{2}$ e $130 \mathrm{~m}^{2}$.

É digna de nota a estabilidade das áreas médias nas cinco primeiras décadas. A variação total no período é de somente $2,2 \%$, enquanto na última década há redução de cerca de $8 \%$ na área média (Figura 6).

Percebe-se também que a área percentual do setor de serviços diminui, com queda mais acentuada a partir dos anos de 1980, enquanto a área social cresce e o setor íntimo, sempre o maior, permanece estável (Figura 7).

\section{Existência, quantificação, percentual e frequência dos cômodos das unidades e por setor da unidade}

Inicialmente verificou-se que todas as 55 unidades possuem os seguintes cômodos, além dos dois ou três dormitórios e um banheiro íntimo exigidos para inclusão no estudo: sala, circulação, cozinha e área de serviço.

No setor social, o vestíbulo está na maioria e o lavabo na minoria das unidades, não refletindo tendência ao longo do tempo. As varandas, aqui incluindo-se sacadas e balcões, eram rarefeitas até o fim dos anos de 1970, e a partir disso sua presença torna-se maciça. No setor íntimo, o fenômeno observado, no caso das suítes, é semelhante: estas eram raras até a década de 1980, e muito presentes a partir de então. Apenas uma unidade da amostra apresenta dois banheiros íntimos sem ter suíte; apenas uma unidade tem duas suítes. As

312 Vespucci, G.; Saboya, R. 
varandas íntimas são ocasionais. Os closets foram considerados parte do dormitório no qual se inserem e sala de estar foram consideradas parte do cômodo "sala". Foi quantificada também a presença da copa junto à cozinha.

Há sala, cozinha, área de serviço, banheiro ${ }^{2}$, circulação íntima e dormitórios (suítes ou não) em todas as unidades. Na sequência, em ordem de predominância, vêm os vestíbulos, com 41 recorrências, os WCs (37), as varandas sociais (34), os quartos de empregada (30) e as suítes (29). Como ambientes minoritários, tem-se copas, varandas íntimas, dormitórios reversíveis e lavabos, todos os últimos com 10 ou menos ocorrências (ver Quadro 1).

A média de cômodos por setor permanece relativamente estável para o setor íntimo, que ganha um banheiro (o da suíte); o setor de serviços perde dois cômodos (WC e dormitório de empregada); e o setor social se aproxima da conformação vestíbulo-sala-varanda (Figura 8).

Figura 6 - Áreas médias das unidades por década

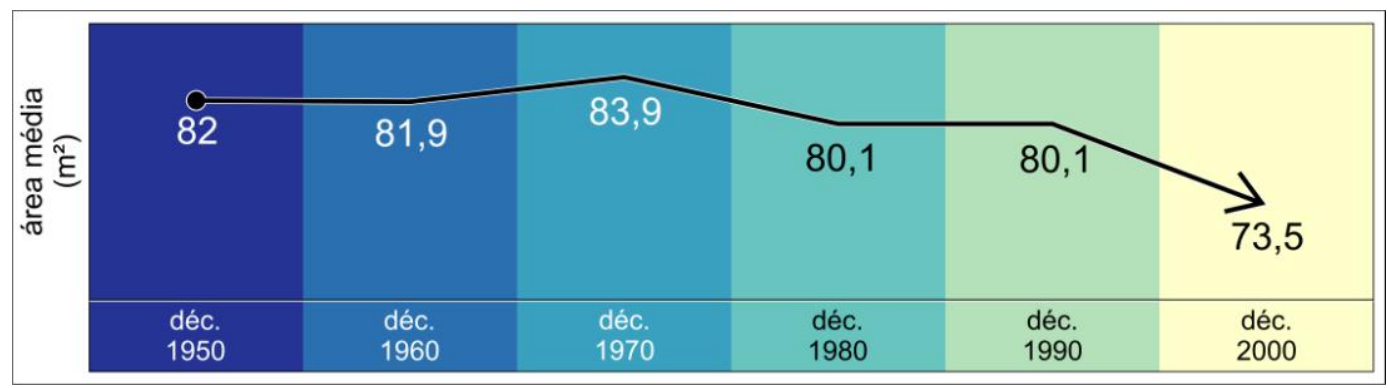

Figura 7 - Percentual dos setores por unidade

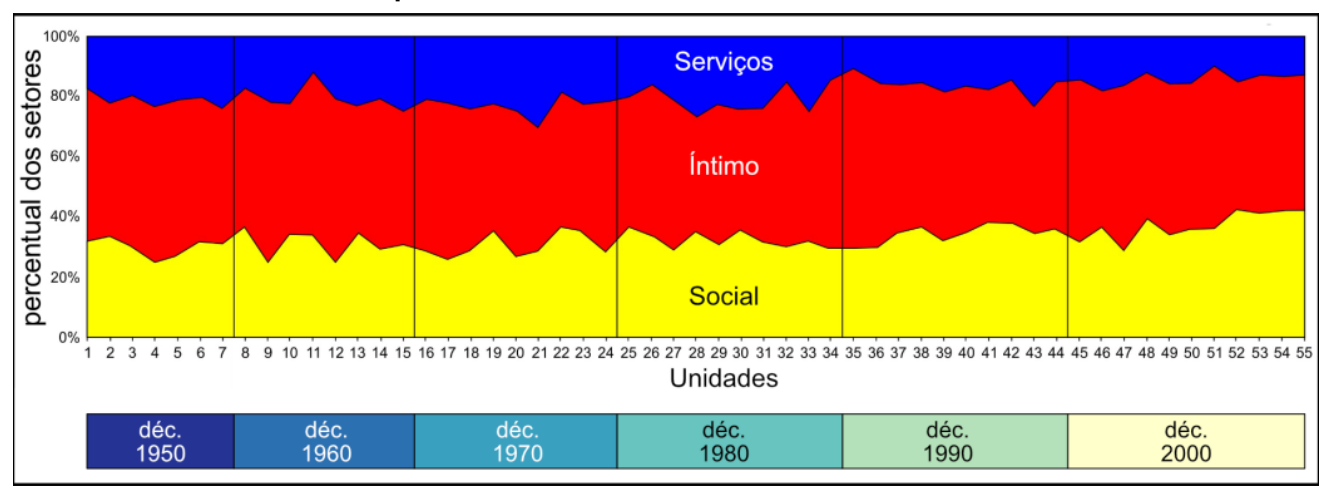

\section{Quadro 1 - Presença de cômodos nas unidades}

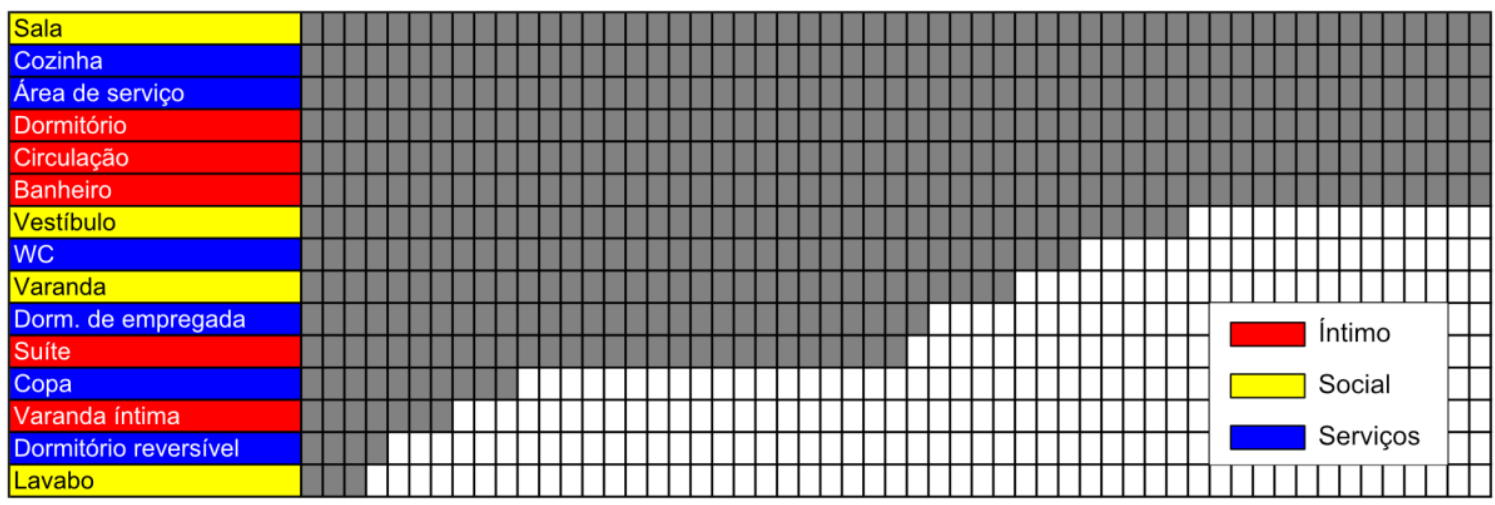

${ }^{2}$ Utilizou-se a denominação "banheiro" para os pertencentes ao setor íntimo, tanto os ligados à circulação quanto os pertencentes às suítes. Aqueles localizados nas áreas de serviços são aqui denominados "WCs". 
Figura 8 - Número médio de cômodos por setor por década

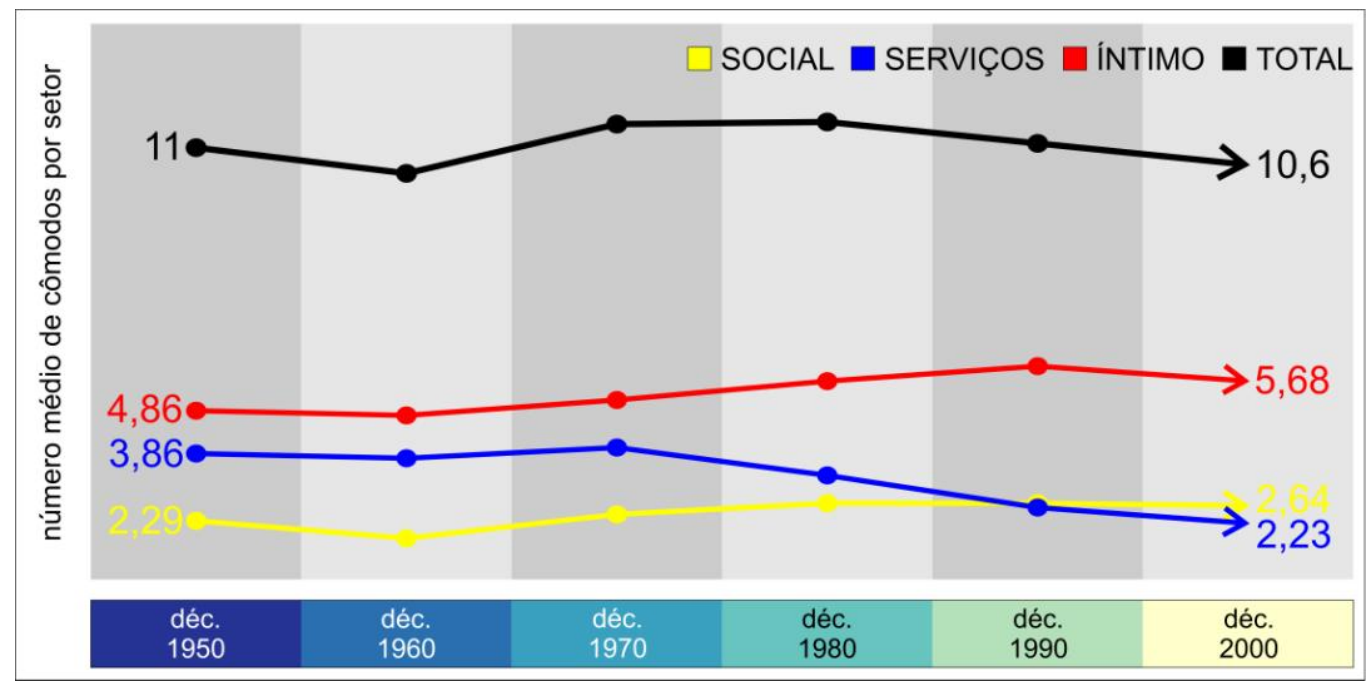

Em termos do percentual de área dos cômodos frente à área da unidade e variação na ocorrência de cômodos, destacam-se os seguintes dados encontrados:

(a) a área percentual da sala cresce ininterruptamente em todo o período, atingindo $14,6 \%$;

(b) a área percentual da varanda social cresce em ritmo acelerado desde a década de 1970 (62\% de incremento). Nas três primeiras décadas, a varanda está em $29 \%$ dos apartamentos; já nas últimas três décadas, aparece em $84 \%$ deles;

(c) no banheiro íntimo há um visível encolhimento programático: a banheira desaparece no início da década de 1970 e o bidê na década seguinte. Como consequência, entre os anos de 1950 e de 1980 a área percentual do banheiro cai $25 \%$;

(d) a área relativa da circulação íntima cai expressivamente: 34\% entre as médias das décadas de 1950 e 2000, o que demonstra, além de um esforço na otimização da área dos cômodos em relação à área de circulação, uma mudança nas relações de privacidade que, antes, eram mais frequentemente mediadas por longos corredores que deixavam os quartos principais mais profundos e reservados em relação à área social;

(e) a previsão do freezer na cozinha expressa nas plantas-baixas ocorre em um curto período entre meados da década de 1990 e início dos anos 2000;

(f) o cômodo (ou subcômodo da cozinha) copa concentra-se prioritariamente até o início da década de 1970, ocorrendo de maneira esparsa após isso;

(g) a existência da entrada secundária, ou entrada de serviço, atinge seu auge nos anos de 1970 (com ocorrência de $88,9 \%$ das unidades). Desaparece duas décadas depois;

(h) a área de serviço sofre algumas mudanças no programa, influenciando seu percentual de área no apartamento. Pode-se extrair 4 fatores de influência no seu arranjo espacial: o advento da máquina de lavar automática, o fim do quarto de empregada e seu respectivo WC, a localização das entradas de serviço (cozinha ou área de serviço) e, por fim, o desaparecimento dessas entradas;

(i) o WC e o dormitório de empregada são presentes em $88 \%$ dos apartamentos até o fim dos anos de 1980; na década de 1990 o WC aparece em $40 \%$ e na última década só se faz presente em 18,2\%. O dormitório de empregada tem destino semelhante, mas mais rapidamente; e

(j) o dormitório de empregada, antes de ser extinto, recebe nova roupagem nos anos de 1980: o dormitório reversível, maior e com acesso a dois setores (de serviços e íntimo).

\section{Aspectos sintático-espaciais}

Há uma grande semelhança nos resultados das médias por década de integração HH e isovista/área. Em ambos os casos os valores são de forte estabilidade entre as décadas de 1950 e 1990, tendo bastante variação positiva apenas na última década do recorte temporal (Figuras 9 e 10). 
Figura 9 - Integração HH média por década

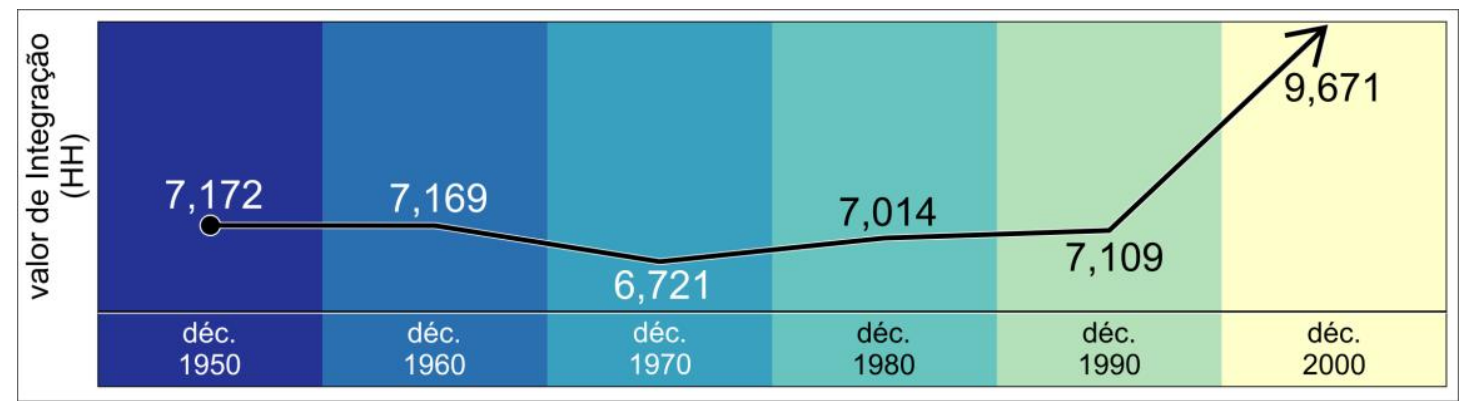

Figura 10 - Isovista/área

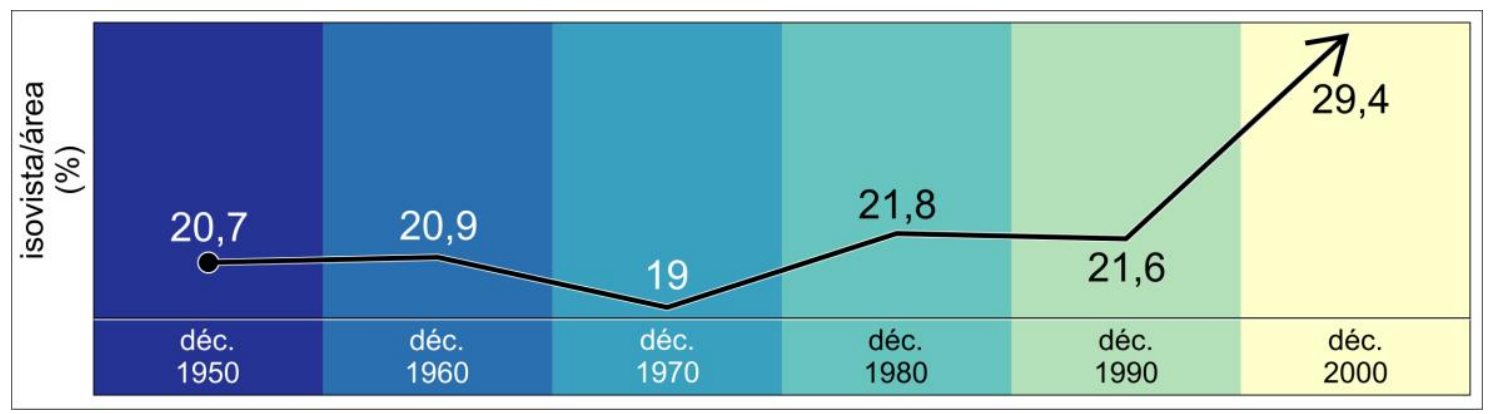

A responsável principal, tanto pelo decréscimo do valor médio nos anos de 1970 quanto pelo grande acréscimo do valor médio de HH na última década, é a relação da cozinha com a sala. A primeira década tem 4 unidades em que a cozinha é acessada apenas pelo setor íntimo; a última engloba 8 unidades com cozinha integrada à sala. Nos anos de 2000, as unidades com cozinha separada da sala apresentam valor de HH igual a 7,422, bem menor do que os 10,514 do valor médio das unidades com cozinha aberta (Tabela 2). Também contribui para isso a diminuição dos corredores e consequente minimização da profundidade dos cômodos íntimos em relação ao resto dos ambientes. Como resultado, o aumento da integração média dos apartamentos por esses dois mecanismos expressa uma diminuição geral das distâncias entre cômodos, que passam a estar mais próximos e acessíveis entre si, especialmente a partir da década de 1990.

A integração sala-cozinha produz os mesmos efeitos nos valores de isovista/área (Iso/A), com aumento substancial na última década. Duas outras características influenciam as Iso/A: área da unidade e número de cômodos. As 8 unidades com maior Iso/A das décadas de 1950 à década de 1990 possuem em média 9,5 cômodos, $68 \mathrm{~m}^{2}$ e 7 das 8 possuem 2 dormitórios; já as 8 unidades com menor Iso/A do mesmo período possuem em média 12,25 cômodos, $94,5 \mathrm{~m}^{2}$ e todas possuem 3 dormitórios.

As medições das IsoPE (isovistas a partir da porta de entrada), realizadas apenas em relação às entradas sociais, seguem a mesma estabilidade por décadas quanto a ocultar ou deixar transparecer o interior dos apartamentos (Figura 11). Novamente, há grande aumento da IsoPE na última década do estudo e novamente há grande influência da relação de continuidade entre sala e cozinha. Interessante notar que a ausência de vestíbulo permite aproximadamente $84 \%$ a mais de visibilidade interna se comparada a unidades com o cômodo (Tabela 3).

A Figura 12 reúne as unidades que tiveram as maiores e as menores IsoPEs, com e sem vestíbulo. Considerando a função de proteger o interior da visibilidade externa, os vestíbulos mais eficazes são os das unidades 7 e 44 . A unidade 7 é a única que separa deliberadamente um espaço para pendurar roupas ou chapéus para a entrada. A 44 ainda permite um pouco de vista para dentro da cozinha e da sala.

Sem vestíbulos, mas com as menores IsoPEs da amostra, são as unidades 21 e 24, ambas da década de 1960. A unidade 21 é a única em que o setor de serviços supera o setor social em área, o que explica a pequena isovista da entrada, que fica restrita à sala. No caso da unidade 24 , a geometria em "L" influencia no fato de nem mesmo a sala ser coberta pela isovista da porta de entrada.

A unidade com o maior vestíbulo (unidade 10) e uma das menores (unidade 51) são as menos eficazes em termos de barreira visual. As isovistas de porta de entrada de ambas, mesmo com vestíbulos, chegam a 
atingir grande parte das áreas sociais e também um pouco da íntima. O vestíbulo da unidade 51 se presta tão somente a proteger a visão da cozinha, enquanto a da unidade 10 é uma antessala por onde se acessa qualquer um dos três setores e permite a visibilidade de quase um terço do apartamento (pouco mais de $32 \%)$.

Por último, as unidades mais devassadas da amostra: a unidade 32, na qual o acesso visual se dá até mesmo à íntegra da varanda da suíte e a unidade 47, na qual a quase metade (precisamente 48,3\%) do apartamento pode ser visualizada a partir da porta de entrada, incluindo toda a sala e varanda, cozinha, boa parte da área de serviço, íntegra da circulação íntima e uma parcela razoável de um dos dormitórios.

Tabela 2 - HH cozinha aberta versus cozinha fechada

\begin{tabular}{l|c}
\hline & $\mathbf{2 0 0 0}$ \\
\hline Valor médio de HH cozinha separada da sala (3 unidades) & 7,422 \\
\hline Valor médio de HH cozinha integrada à sala (8 unidades) & 10,5144 \\
\hline
\end{tabular}

Figura 11 - IsoPE por décadas

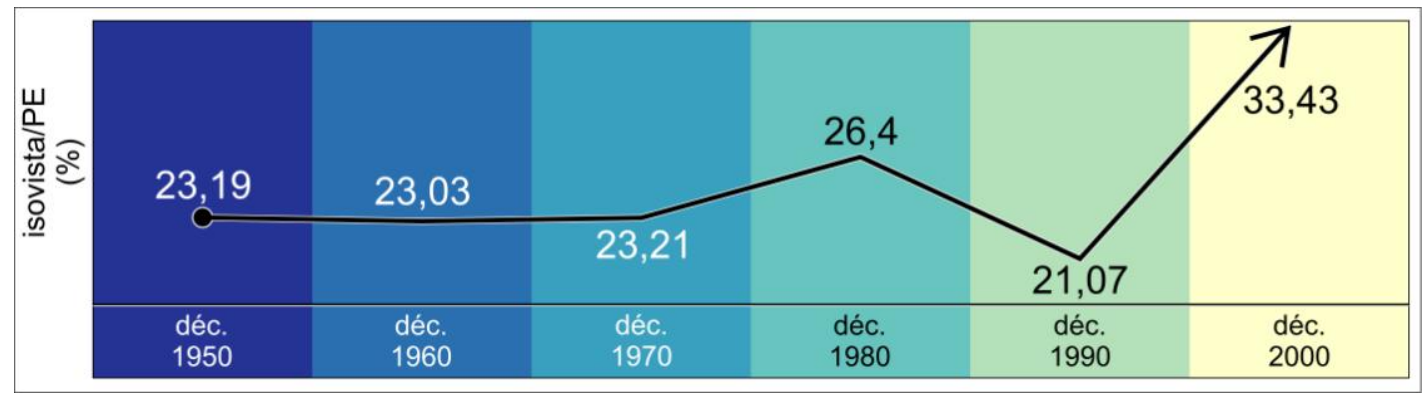

Tabela 3 - IsoPE por tipologia

\begin{tabular}{l|c|c}
\hline Tipologia & Ocorrências & IsoPE médio \\
\hline Com vestíbulo & 40 & $20,84 \%$ \\
\hline Sem vestíbulo & 15 & $38,27 \%$ \\
\hline
\end{tabular}

Figura 12 - Isovista versus existência de vestíbulos
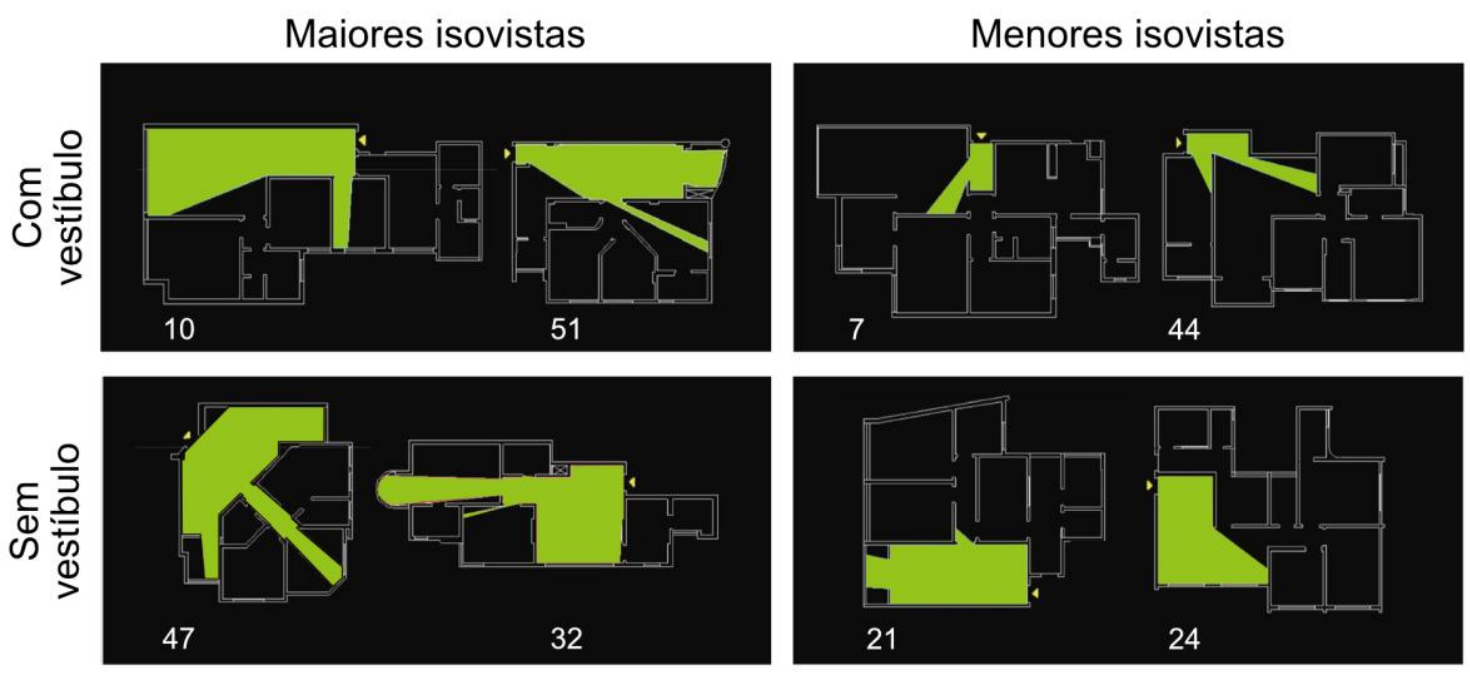

316 Vespucci, G.; Saboya, R. 


\section{Forma dos grafos justificados simplificados}

Da análise sobre os grafos completos em sua complexidade direcionada somente aos setores, extrai-se como resultado gráfico as figuras superiores da Figura 13. A partir da simplificação de cada um dos 55 grafos justificados completos, emergem quatro tipos, cuja gênese é explicada com base na figura (com dois exemplos acima de cada tipo). Todos os grafos justificados completos, quando simplificados apenas com o enfoque dos setores, resumem-se a tipos de sistema configuracional. Todos eles têm como raiz a parte externa social e, por isso, apresentam como primeiro passo topológico a área social da unidade. A partir de então se diferenciam. No tipo 1 partem ligações do setor social para os dois outros setores, íntimo e de serviços, mas sem haver uma ligação entre os últimos. A presença de tal ligação diferencia o tipo 2 do 1 . Nesse segundo tipo notamos um ou mais anéis de circulação passando pelos três setores. O tipo 3 é em esquema linear: para se chegar ao setor de serviços é preciso passar, necessariamente, pelo setor íntimo. O tipo 4 é uma variação do tipo 2, no qual há uma transição ou um setor misto entre os setores íntimo e de serviços, que é justamente o cômodo chamado de dormitório reversível (servindo opcional ou simultaneamente para funções de ambos os setores).

Ao longo do tempo, o tipo 1 é predominante. Nas duas primeiras décadas, as duas unidades do tipo 2 e a única unidade do tipo 3 se referem a projetos do mesmo arquiteto. A amostra da década de 1970 faz emergir um arranjo que exclui o acesso entre os setores social e o de serviços. Quatro unidades daquela época são do tipo 3. Com a década de 1980 surgem os dormitórios reversíveis, já um prenúncio de seu fim, e com eles o tipo 4, com três exemplares e mais um remanescente já na década de 2000. Além do tipo 2, o tipo 4 também contém necessariamente anel de circulação cruzando três setores. O tipo 1 representa $71 \%$ da amostra e $82 \%$ da última década (Figura 14).

Conforme se observa na Tabela 4 , todos os principais cômodos da casa possuem crescimento absoluto nos valores de $\mathrm{HH}$ na última década, com maior intensidade em relação à cozinha $(80 \%)$, à área de serviço $(67 \%)$, à sala (38\%), à circulação $(37 \%)$ e ao vestíbulo (33\%). O fato de os dois primeiros serem ambientes de serviços, historicamente os mais segregados, outra vez revela como a eliminação de barreiras entre cozinha e sala alteram significativamente as propriedades sintático-espaciais.

Figura 13 - Tipos de grafos

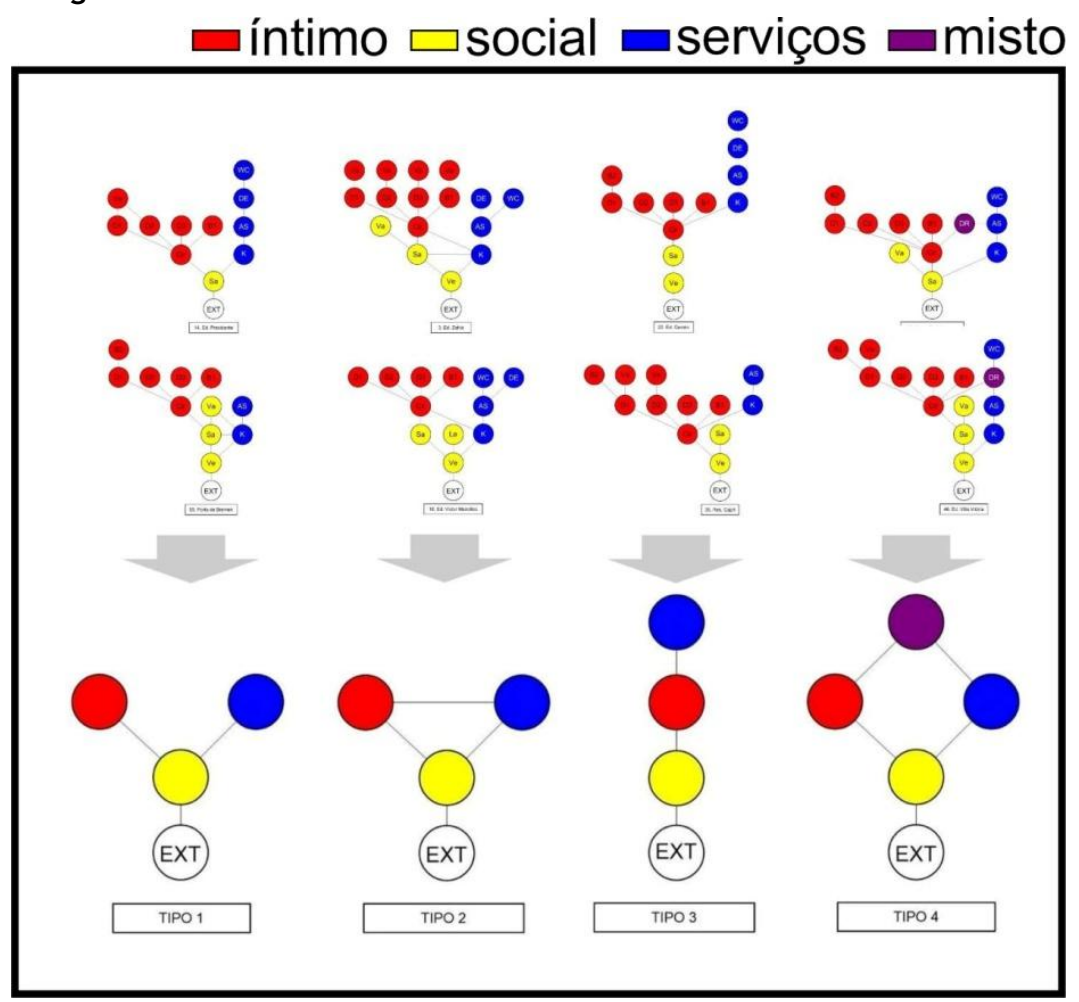


Figura 14 - Tipos de sistemas configuracionais por décadas

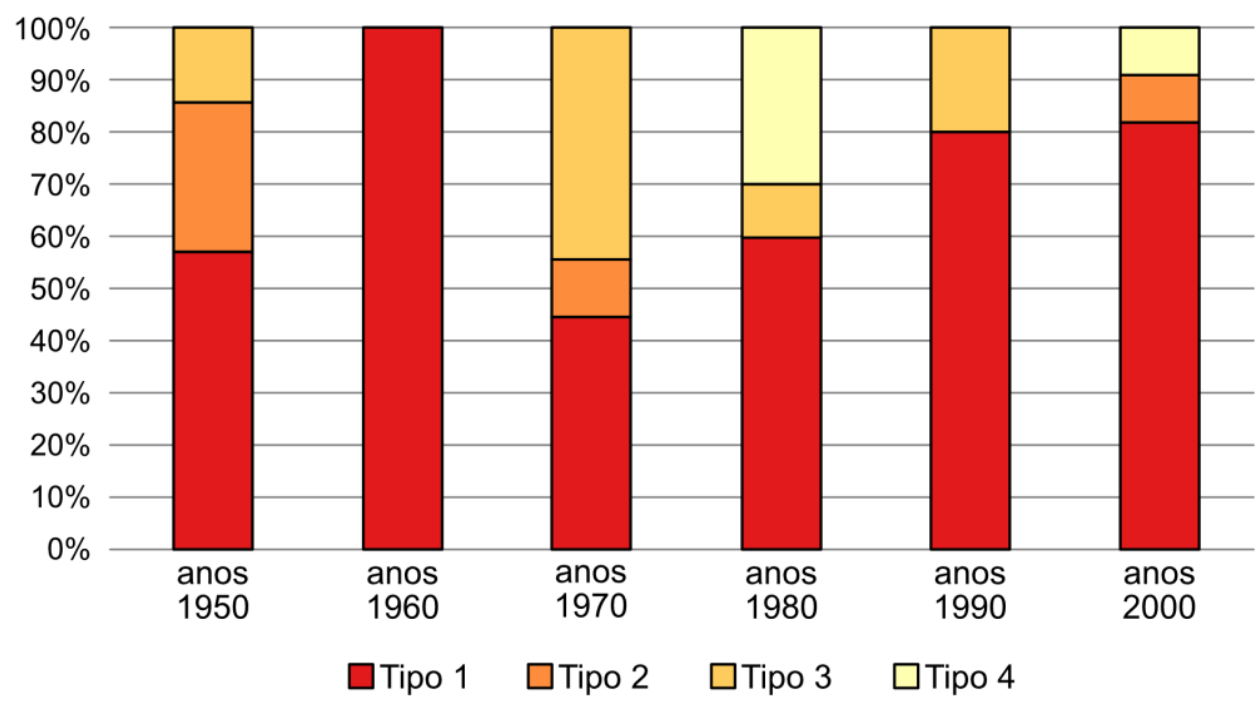

Tabela 4 - HH valores médios

\begin{tabular}{l|c|c|c|c|c|c}
\hline \multicolumn{1}{|c|}{ SETOR SOCIAL } & $\mathbf{1 9 5 0}$ & $\mathbf{1 9 6 0}$ & $\mathbf{1 9 7 0}$ & $\mathbf{1 9 8 0}$ & $\mathbf{1 9 9 0}$ & $\mathbf{2 0 0 0}$ \\
\hline HH sala & & & & & & \\
\hline HH vestíbulo & 8,55 & 9,22 & 8,44 & 8,89 & 9,01 & 12,43 \\
\hline HH varanda & 7,74 & 7,65 & 7,01 & 7,64 & 8,12 & 10,82 \\
\hline$\quad$ SETOR ÍNTIMO & $6,04 *$ & $-*$ & 6,54 & 6,29 & 7,44 & 9,16 \\
\hline HH circulação & & & & & & \\
\hline HH dormitórios (média) & 9,8 & 9,48 & 9,23 & 9,63 & 9,42 & 12,9 \\
\hline HH banheiros (média) & 6,4 & 6,33 & 6,13 & 6,25 & 6,5 & 7,55 \\
$\quad$ SETOR DE SERVIÇOS & & 6,12 & 5,72 & 5,41 & 5,6 & 6,29 \\
\hline HH cozinha & 7,04 & 6,13 & 6,55 & 6,32 & 5,98 & 10,76 \\
\hline HH área de serviço & 5,07 & 5,52 & 5,23 & 5,29 & 4,48 & 7,47 \\
\hline
\end{tabular}

Nota: *quantidade desprezível.

Com a metodologia utilizada, verificou-se que as plantas representadas na Figura 15, de 1954/1967 e de 2005/2008, respectivamente, sintetizam as mudanças encontradas no interior dos apartamentos. No setor de serviços, além da diminuição do número de cômodos (dormitório de empregada e WC de serviços são excluídos), há o fim das barreiras visuais e ao movimento entre cozinha e sala. Também há a extinção da segunda entrada para a unidade, a entrada de serviços, localizada na cozinha ou na área de serviços. Na área íntima, há o surgimento do segundo banheiro e da suíte. No setor social, há o aumento de 2 para 3 no número médio de cômodos, com presença constante da varanda.

Na comparação entre os setores, cabe destaque a alguns pontos. Poucas alterações morfológicas ou sintáticas são percebidas no setor íntimo. Sua área percentual nas unidades se mantém estável e seus cômodos continuam possuindo baixos valores de integração e isovista. As funções dos cômodos e seu posicionamento dentro da unidade permanecem os mesmos. Entretanto, aponta-se como diferencial o surgimento das suítes, com o acréscimo de um banheiro junto ao maior dormitório. Dentro dos banheiros consolida-se a extinção das banheiras no início dos anos 70 e, posteriormente, dos bidês.

O setor de serviço diminui pela extinção de quartos e banheiros de empregada, à medida que as famílias prescindem da figura da empregada doméstica, substituindo-a, aos poucos, pela da diarista. Ressalte-se que o quarto de empregada, antes de desaparecer, converte-se a um ambiente reversível, como escritório, quarto de hóspede, closet ou depósito. Esta última função foi transposta, já nos anos 2000, à garagem, sob a denominação hobby box. Da mesma forma, o menor uso do freezer provocado pelos apagões de 1999 e 2001 e a diminuição da necessidade de armazenamento, pelo fim da inflação, associados à ausência de empregada doméstica, induziram à diminuição da área das cozinhas e à supressão de copas junto às cozinhas.

318 Vespucci, G.; Saboya, R. 
Figura 15 - Síntese das mudanças

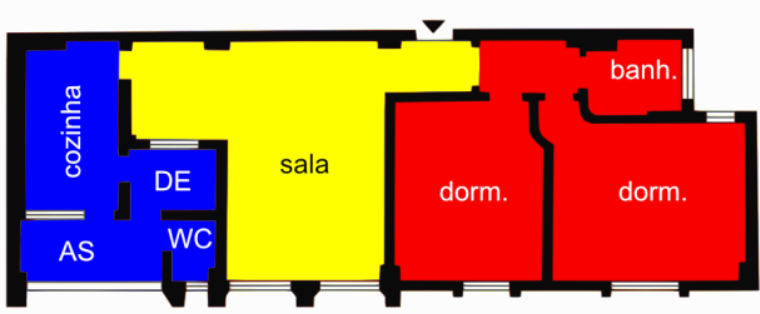

Ed. Meridional (1954)

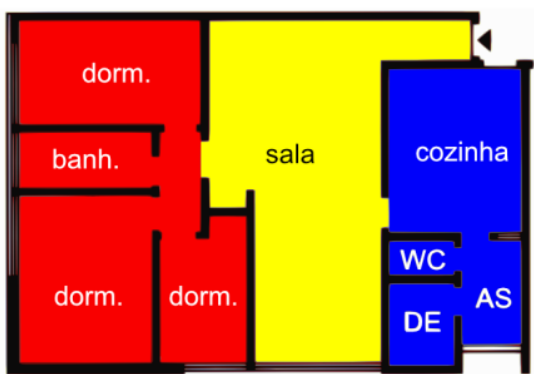

Ed. Solar Dona Martha (1967)

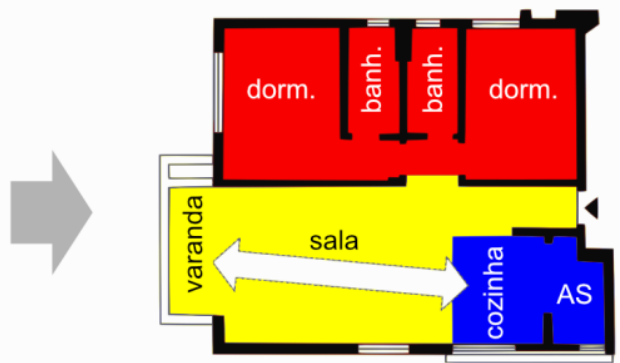

Ed. Isola D'Oro (2005)

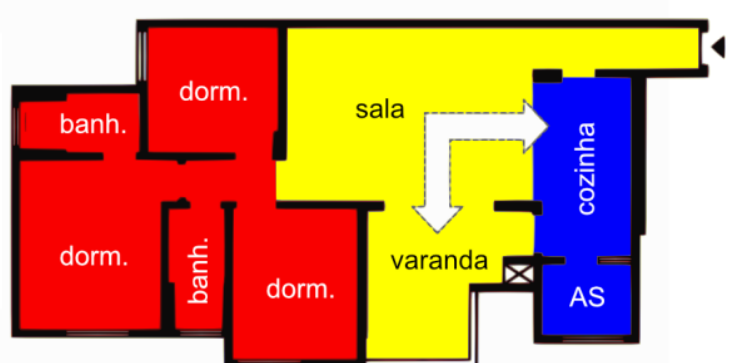

Ed. Porto de Bremen (2008)

Parcela da área retirada do setor de serviços foi adicionada à do setor social. A interiorização da vida social e seu distanciamento dos espaços públicos de convívio também parecem explicar parte das modificações encontradas, tais como a ampliação das áreas sociais e sua integração às cozinhas, bem como o aumento da área e a mudança funcional nas varandas. Atividades que antes eram feitas fora de casa, tais como almoços e jantares em restaurantes, agora são mais comuns nos espaços residenciais. No início dos anos 1970 a varanda passa a atingir a quase totalidade das unidades, sendo que nos anos 2000 destacam-se o aumento de sua área, da área da sala e o fim das barreiras visuais entre ambas e a cozinha.

\section{Considerações finais}

As mudanças encontradas apontam alterações importantes nas maneiras como as pessoas veem e se comportam no espaço residencial, bem como na relação deste com o espaço público. Talvez a mudança mais marcante seja o desaparecimento da entrada de serviço, que reflete alterações no perfil socioeconômico da população de diferentes estratos socioeconômicos, assim como nas alterações familiares e nas relações trabalhistas e nos desdobramentos do debate sobre racismo e exploração feminina. O fim do quarto de empregada se insere no mesmo contexto.

Mais recentemente, por outro lado, a varanda assume protagonismo no apartamento ao ter majorada a sua área e por adquirir função de preparo e consumo de alimentos, sendo uma extensão da sala e, em alguns casos, tendo ligação direta com a cozinha.

É possível que esse hábito volte a se modificar com a tendência aparente de criação de espaços de convívio na escala dos condomínios, tais como espaços gourmet, playgrounds e salas de cinema, aspectos não incluídos neste estudo. Por enquanto, vê-se que isovistas maiores de certa forma "compensam" as áreas menores dos apartamentos vistas na última década. Isso se dá graças à menor compartimentação, com menor preocupação de se evitar eixos visuais livres no interior das unidades habitacionais. O mesmo vale para as isovistas a partir da porta de entrada, cujo índice, somente na última década estudada, aumenta em 33\%. A varanda com funções de lazer e cozinha concedeu aumento de centralidade e acessibilidade à área social.

Enfim, as análises do período estudado mostraram que a década de 1980 se destaca no âmbito das variações no campo morfológico, relacionadas às funções de serviço e à figura da empregada doméstica, e a década de 2000 promove as maiores alterações em termos de dimensões sintáticas, principalmente pela integração cozinha-sala-varanda.

Essas alterações estão profundamente relacionadas a mudanças significativas no contexto socioeconômico e cultural brasileiro, e expressam claramente a maneira pela qual aspectos sociais se refletem na forma e 
configuração do espaço. Um modo de vida mais hierarquizado e com separação clara entre setores (e usuários) do espaço habitacional vem, aos poucos, dando lugar a uma estrutura mais horizontalizada e integrada, em que os espaços de serviços têm se aproximado das áreas sociais, tanto espacialmente quanto no que diz respeito às atividades e relações sociais ali estabelecidas. Assim, a tendência à interiorização da vida social se expressa no espaço da residência: seus espaços interiores se descortinam mais aos visitantes, que, mesmo eventuais, podem apreender com apenas um olhar uma proporção maior da unidade; as cozinhas passam a ser utilizadas pelos próprios moradores, e não pelas empregadas domésticas, e, portanto, passam a integrar-se mais diretamente à sala; a varanda segue o mesmo movimento, passando a funcionar como espaço de socialização. Paralelamente, a massificação desse tipo de unidade residencial teve como um de seus efeitos, além da verticalização das cidades, o enxugamento das áreas construídas e uma busca pela otimização dos espaços. Não fica claro se foi isso que levou a uma maior integração visual dos espaços internos ou se a direção foi inversa, ou ainda se ambas as tendências se reforçaram mutuamente a partir de mecanismos relativamente independentes. As mudanças, entretanto, foram claras, e permitem colocar em perspectiva essa inter-relação entre fatores socioeconômicos e sua expressão espacial, estimulando ainda a reflexão sobre quais são esses fatores atualmente (por exemplo, com a explosão das redes sociais e novas formas de contatos não necessariamente mediados pelo espaço) e suas possíveis consequências para a estrutura das unidades habitacionais. Para além desse cenário tendencial, entretanto, cabe perguntar-se não apenas quais são as possíveis consequências das mudanças atualmente em curso, mas também como trabalhar para que o espaço construído não seja apenas o reflexo de fatores determinados de cima, mas que possa dialogar com esses fatores na busca por espaços e socialidades mais justas, enriquecedoras e democráticas.

\section{Referências}

ALVES, J. E. D. As características dos domicílios brasileiros entre 1960 e 2000. Textos para Discussão, n. 10, 2004. Disponível em: https://biblioteca.ibge.gov.br/visualizacao/livros/liv3124.pdf. Acesso em: 13 fev. 2013.

BERQUÓ, E. Arranjos familiares no Brasil: uma visão demográfica. In:HISTÓRIA da Vida privada no Brasil. São Paulo: Companhia das Letras, 1998.

BRANDÃO, D. Q. Tipificação e aspectos morfológicos de arranjos espaciais de apartamentos no âmbito da análise do produto imobiliário brasileiro. Ambiente Construído, Porto Alegre, v. 3, n. 1, p. 35-53, jan./mar. 2003.

BRANDÃO, D. Q.; HEINECK, L. F. M. Diversidade de arranjos espaciais de apartamentos no Brasil: duas formas de análise, duas diferentes conclusões. In: CONFERÊNCIA LATINO-AMERICANA DE CONSTRUÇÃO SUSTENTÁVEL; ENCONTRO NACIONAL DE TECNOLOGIA DO AMBIENTE CONSTRUÍDO, 10., São Paulo, 2004. Anais [...] São Paulo, 2004.

BRAUDEL, F. Civilização material, economia e capitalismo, séculos XV-XVIII: I. As estruturas do cotidiano. São Paulo: Martins Fontes, 1995.

BRUAND, Y. Arquitetura Contemporânea no Brasil. 4. ed. São Paulo: Perspectiva, 2002.

CUNHA, V. Can genotype patterns change over time? In: GREENE, M.; REYES, J.; CASTRO, A. (ed.). In: INTERNATIONAL SPACE SYNTAX SYMPOSIUM, 8., Santiago, 2012. Proceedings [...] Santiago: PUC, 2012.

DAWSON, P. C. Space syntax analysis of Central Inuit snow houses. Journal of Anthropological Archaeology, v. 21, n. 4, p. 464-480, 2002.

ELEB, M. Généalogie de l'habitation et histoire sociale. In: FROMMEL, S. (org.). Méthodes en histoire de l'architecture. Paris: Monum, 2002.

EVANS, G. W.; LEPORE, S. J.;SCHROEDER, A. The role of interior design elements in human responses to crowding. Journal of Personality and Social Psychology, v. 70, n. 1, p. 41-46, 1996.

GRIZ, C. Quando o luxo é necessário: sobre projetos de apartamentos no Recife. Recife, 2012. Tese (Doutorado em Desenvolvimento Urbano) - Universidade Federal de Pernambuco, Recife, 2012.

GÜNEY, Y. I. Analyzing visibility structures in Turkish domestic spaces. In: INTERNATIONAL SPACE SYNTAX SYMPOSIUM, 8., Istanbul, 2007. Proceedings [...] Istanbul, 2007.

HANSON, J. Decoding homes and houses. Cambridge: Cambridge University Press, 1998.

320 Vespucci, G.; Saboya, R. 
HILLIER, B.; HANSON, J. The social logic of space. Cambridge: Cambridge University Press, 1984. INSTITUTO BRASILEIRO DE GEOGRAFIA E ESTATÍSTICA. Síntese de indicadores sociais: uma análise das condições de vida da população brasileira. Rio de Janeiro, 2010.

INSTITUTO BRASILEIRO DE GEOGRAFIA E ESTATÍSTICA. Pesquisa Nacional por Amostra de Domicílios Contínua: tabelas - 2018, características gerais dos domicílios e dos moradores. Rio de Janeiro, 2019. Disponível em: https:/www.ibge.gov.br/estatisticas/sociais/populacao/17270-pnadcontinua.html?edicao=24437\&t=resultados. Acesso em: 15 fev. 2020.

LEMOS, C. A. C. História da casa brasileira. 2. ed. São Paulo: Contexto, 1996.

LEWCOCK, R. WadiHadramawt and the walled city of Shibam. Paris: Unesco, 1986.

MANCINI, G. A. Avaliação dos custos da urbanização dispersa do Distrito Federal. Brasília, 2008. Dissertação (Mestrado em Arquitetura e Urbanismo) - Faculdade de Arquitetura e Urbanismo, Universidade de Brasília,Brasília, 2008.

MILES, M. B.; HUBERMAN, A. M. Qualitative data analysis. Thousand Oaks: Sage Publications, 1994.

PEDRO, J. B. Programa habitacional: espaços e compartimentos. Lisboa: LNEC, 1999.

PERROT, M. Maneiras de morar. In: ARIÉS, P.;DUBY, G. (org.). História da vida privada: da Revolução Francesa à Primeira Guerra. São Paulo: Companhia das Letras, 1992.

PINHO, Â. C. Apartamentos e mídias em Belo Horizonte. São Carlos, 2005. Dissertação (Mestrado em Arquitetura e Urbanismo) - Escola de Engenharia de São Carlos, Universidade de São Paulo, São Carlos, 2005.

QUEIROZ, F. A. Apartamento modelo: arquitetura, modos de morar e produção imobiliária em São Paulo.São Carlos, 2008.Dissertação (Mestrado em Arquitetura e Urbanismo) - Escola de Engenharia de São Carlos, Universidade de São Paulo, São Carlos, 2008.

QUEIROZ, F.; TRAMONTANO, M. Apartamentos paulistanos: um olhar sobre a produção privada recente. Ambiente Construído, Porto Alegre, v. 9, n. 2, p. 139-150, abr./jun. 2009.

RAMIRES, J. C. de L. O processo de verticalização das cidades brasileiras.Boletim de Geografia, v. 16, n. 1, p. 97-106, jan. 2011.

RAPOPORT, A. House Form and Culture. Englewood Cliffs: Prentice-Hall, 1969.

REIS FILHO, N. G. Quadro da arquitetura no Brasil. 5. ed. São Paulo: Perspectiva, 1983.

REQUENA, C. A. J. Habitar Híbrido: interatividade e experiência na era da cibercultura. São Carlos, 2007. Dissertação (Mestrado em Arquitetura e Urbanismo) - Escola de Engenharia de São Carlos, Universidade de São Paulo, São Carlos, 2007.

SABOYA, R. et al. Padrões de visibilidade e permeabilidade em espaços públicos abertos: um estudo sintático em Curitiba - PR. Arquitextos - Vitruvius, v. 164, n. 1, 2014.

SCHNEIDER, F. (ed.). Atlas de Plantas: viviendas. 2. ed. Barcelona: Ed. Gustavo Gili, 1998.

SEGAWA, H. Arquiteturas no Brasil: 1900-1990. 2. ed. São Paulo: EDUSP, 2002.

SPERLING, D. M. Entre conceitos, metáforas e operações: convergências da topologia na arquitetura contemporânea. Gestão \& Tecnologia de Projetos, v. 3, n. 2, p. 24-55, 2008.

TRAMONTANO, M. C. Espaços domésticos flexíveis: notas sobre a produção da primeira geração de modernistas brasileiros. São Paulo: FAU/USP, 1993. Texto técnico.

VAN HOOGDALEM, H.; VAN DER VOORDT, T. J. M.; VAN WEGEN, H. B. R. Comparative floorplananalysis as a means to develop design guidelines. Journal of Environmental Psychology, v. 5, n. 2, p. 153 $179,1985$.

VAUTHIER, L. L. Casas de residência no Brasil. In: SMITH, R. C. Arquitetura Civil I: textos escolhidos da Revista do Patrimônio Histórico e Artístico Nacional. São Paulo: MEC-IPHAN, 1981.

VILLA, S. B. Mercado imobiliário e edifícios de apartamentos: produção do espaço habitável no século XX. In: SEMINÁRIO INTERNACIONAL DA LARES, 4., São Paulo, 2004. Anais [...] São Paulo:LARES, 2004. 
VILLA, S. B. Morar em apartamentos: a produção dos espaços privados e semi-privados nos edifícios ofertados pelo mercado imobiliário no século XXI em São Paulo e seus impactos na cidade de Ribeirão Preto. Critérios para avaliação pós-ocupação. São Paulo, 2008. Tese (Doutorado em Arquitetura e urbanismo) - Universidade de São Paulo,São Paulo, 2008.

WIENER, J. M.; FRANZ, G. Isovistsas as means to predict spatial experience and behavior. In: FREKSA, C. et al. (eds.). Spatial Cognition IV. Reasoning, Action, Interaction.Berlin: Springer, 2005. v. 3343, p. $42-57$.

\section{Gabriel Vespucci}

Depto Arquitetura e Urbanismo | Universidade Federal de Santa Catarina | Campus Reitor João David Ferreira Lima | Florianópolis - SC Brasil | CEP 88040-900 | Tel.: (48)3721-4860 | E-mail: gmvsp@hotmail.com

\section{Renato Saboya}

Departamento Arquitetura e Urbanismo | Universidade Federal de Santa Catarina | E-mail: renato.saboya@ufsc.br

\section{Ambiente Construído}

Revista da Associação Nacional de Tecnologia do Ambiente Construído

Av. Osvaldo Aranha, $99-3^{\circ}$ andar, Centro

Porto Alegre - RS - Brasil

$$
\text { CEP } 90035-190
$$

Telefone: +55 (51) 3308-4084

Fax: +55 (51) 3308-4054

www.seer.ufrgs.br/ambienteconstruido

E-mail: ambienteconstruido@ufrgs.br 